\title{
Distribution of Malassezia species on the skin of patients with atopic dermatitis, psoriasis, and healthy volunteers assessed by conventional and molecular identification methods
}

Tomasz Jagielski ${ }^{1 *}$, Elżbieta Rup ${ }^{2}$, Aleksandra Ziółkowska ${ }^{1}$, Katarzyna Roeske ${ }^{1}$, Anna B Macura ${ }^{2}$ and Jacek Bielecki ${ }^{1}$

\begin{abstract}
Background: The Malassezia yeasts which belong to the physiological microflora of human skin have also been implicated in several dermatological disorders, including pityriasis versicolor (PV), atopic dermatitis (AD), and psoriasis (PS). The Malassezia genus has repeatedly been revised and it now accommodates 14 species, all but one being lipid-dependent species. The traditional, phenotype-based identification schemes of Malassezia species are fraught with interpretative ambiguities and inconsistencies, and are thus increasingly being supplemented or replaced by DNA typing methods. The aim of this study was to explore the species composition of Malassezia microflora on the skin of healthy volunteers and patients with AD and PS.
\end{abstract}

Methods: Species characterization was performed by conventional, culture-based methods and subsequently molecular techniques: PCR-RFLP and sequencing of the internal transcribed spacer (ITS) 1/2 regions and the D1/D2 domains of the 265 rRNA gene. The Chi-square test and Fisher's exact test were used for statistical analysis.

Results: Malassezia sympodialis was the predominant species, having been cultured from 29 (82.9\%) skin samples collected from 17 out of 18 subjects under the study. Whereas AD patients yielded exclusively M. sympodialis isolates, M. furfur isolates were observed only in PS patients. The isolation of M. sympodialis was statistically more frequent among AD patients and healthy volunteers than among PS patients $(P<0.03)$. Whether this mirrors any predilection of particular Malassezia species for certain clinical conditions needs to be further evaluated. The overall concordance between phenotypic and molecular methods was quite high (65\%), with the discordant results being rather due to the presence of multiple species in a single culture (co-colonization) than true misidentification. All Malassezia isolates were susceptible to cyclopiroxolamine and azole drugs, with M. furfur isolates being somewhat more drug tolerant than other Malassezia species.

Conclusions: This study provides an important insight into the species composition of Malassezia microbiota in human skin. The predominance of M. sympodialis in both normal and pathologic skin, contrasts with other European countries, reporting M. globosa and M. restricta as the most frequently isolated Malassezia species.

Keywords: Identification, Malassezia spp, PCR-RFLP, Sequence analysis, Drug susceptibility

\footnotetext{
* Correspondence: t.jagielski@biol.uw.edu.pl

'Department of Applied Microbiology, Institute of Microbiology, Faculty of Biology, University of Warsaw, I. Miecznikowa 1, 02-096 Warsaw, Poland

Full list of author information is available at the end of the article
} 


\section{Background}

The fungi of the Malassezia genus, whose first description dates back to the middle of the XIX century, have only recently gained considerable attention of the dermatological community. This is because those basidiomycetous yeasts, being components of the microbiota of human and animal skin and constituting up to $80 \%$ of the total skin fungal population [1] are now increasingly recognized as opportunistic pathogens resulting in different dermatological pathologies. Malassezia yeasts are the causative agents of pityriasis versicolor (PV), which is one of the commonest superficial mycoses in human population worldwide [2]. Malassezia species are also involved in the pathogenesis of various dermatoses with global distribution, such as seborrheic dermatitis $(\mathrm{SD})$, atopic dermatitis (AD), and, more recently, psoriasis (PS) [3-6]. A growing number of reports demonstrate the implication of Malassezia yeasts in other skin disorders, including folliculitis, onychomycosis, confluent and reticulated papillomatosis, and neonatal cephalic pustulosis [7-10]. Finally, Malassezia yeasts have been associated with systemic infections and outbreaks in neonatal and immunocompromised adults intensive care units $[11,12]$.

The species content of the Malassezia genus has repeatedly been revised over the last two decades. In the early 1990s the genus Malassezia contained only three species, namely $M$. furfur, $M$. pachydermatis, and $M$. sympodialis. In 1996, four other species (i. e. M. globosa, M. obtusa, M. restricta, and M. slooffiae) were identified within the genus, through a comparative sequence analysis of nuclear ribosomal DNA (rDNA) operons [13]. Since 2002 seven more new species have been described, on the basis of molecular data: M. dermatis, M. equina, M. japonica, M. nana, M. yamatoensis, M. caprae, and M. cuniculi [14-19]. Overall, the genus Malassezia now accommodates 14 species, all but one (M. pachydermatis) being lipid-dependent species.

Among the Malassezia species, one of the most frequently isolated is $M$. sympodialis, which has been considered to be associated with $\mathrm{AD}$. One of the clearest indications to support this is the fact that almost half of the adult patients suffering from $\mathrm{AD}$ are sensitized to $M$. sympodialis, as evidenced by allergen-specific IgE and/or $\mathrm{T}$-cell reactivity to the yeast, and that such reactivity is rarely observed in other allergic diseases [20,21].

The identification of most of Malassezia species can be achieved by using a combination of morphological, biochemical, and physiological characteristics. The currently used protocol, based on the phenotypic criteria, includes the examination of colony and cell morphology, determination of urease, catalase, and $\beta$-glucosidase activities, growth at $37^{\circ} \mathrm{C}$ and $40^{\circ} \mathrm{C}$, and the capacity to grow with different polyoxyethylene sorbate compounds
(Tween 20,40,60,80) and polyoxyethylene castor oil (Cremophor EL), as the sole lipid source [22].

With the advent of molecular biology tools, several new, DNA-targeted methods have been developed and tested for species identification within the Malassezia taxon. These include pulsed-field gel electrophoresis (PFGE) [23,24], randomly amplified polymorphic DNA (RAPD) analysis [23,25], amplified fragment length polymorphism (AFLP) analysis $[25,26]$, denaturing gradient gel electrophoresis (DGGE) [25], multilocus enzyme electrophoresis (MEE) [27], PCR-based single strand confirmation polymorphism (PCR-SSCP), PCRbased restriction fragment length polymorphism (PCRRFLP) [7,28-34], nested PCR [32,35-37], real-time (RT) PCR $[35,38]$, and direct sequencing of various genetic loci, such as rDNA and internal transcribed spacer (ITS) 1 and 2 regions in particular, the chitin synthase (CHS2) gene, and the RNA polymerase subunit 1 (RPB1) gene [18,26,39-41].

The purpose of this study was to explore the species composition of Malassezia microflora on the skin of healthy volunteers and patients with AD and PS. Species determination was performed by using both conventional, culture-based methods and molecular techniques, that is PCR-RFLP and direct sequencing targeting the rDNA cluster of the Malassezia genome.

\section{Methods \\ Subjects}

The study group comprised of 18 subjects (8 (44.4\%) males and $10(55.6 \%)$ females, aged from $22-70$ years; mean age: 34.8 years; median age: 30 years), all being Polish and living in the Lesser Poland province. The subjects were split into three, equally sized groups (i.e. six subjects per each group), consisting of healthy volunteers (i) and patients diagnosed with either atopic dermatitis (ii) or psoriasis (iii). Both AD and PS patients were recruited from the routine dermatology outpatient clinic at the Collegium Medicum of the Jagiellonian University in Kraków, where they were assessed clinically and received treatment during a 3-year period (2008-2010). The diagnosis of AD was made according to the Hanifin-Rajka criteria [42], and the severity of the disease was categorized based on the Severity Scoring of Atopic Dermatitis (SCORAD) index [43]. The diagnosis of PS was based on clinical features and confirmed by histopathological analysis. The severity of psoriatic lesions was evaluated using the Body Surface Area (BSA) and Psoriasis Area and Severity (PASI) indexes $[44,45]$.

Information on demographic characteristics and clinical aspects of the disease were collected in a standardized questionnaire by reviewing the medical records and analysed (Table 1). 
Table 1 Characteristics of 18 subjects under the study and microbiological details of $\mathbf{3 5}$ isolated Malassezia species

\begin{tabular}{|c|c|c|c|c|c|c|c|c|c|c|c|c|c|}
\hline & Patient $^{a}$ & $\begin{array}{l}\text { Subject } \\
\text { group }^{b}\end{array}$ & $\begin{array}{l}\text { Collection } \\
\text { site }\end{array}$ & Sex & Age & $\begin{array}{l}\text { Lesion } \\
\text { severity }^{d}\end{array}$ & Episode $^{\mathrm{e}}$ & $\begin{array}{l}\text { Duration of } \\
\text { disease [yrs] }\end{array}$ & Treatment $^{f}$ & $\begin{array}{l}\text { Family history of } \\
\text { disease }\end{array}$ & Other diseases $^{g}$ & $\begin{array}{l}\text { Strain } \\
\text { no. }\end{array}$ & $\begin{array}{l}\text { Species } \\
\text { identifiction }^{h}\end{array}$ \\
\hline 1. & TK & $A D$ & Head & M & 24 & 37 & $R$ & 24 & Topical; sys: & Positive & No & 40.10 .1 & M. sympodialis \\
\hline 2. & & & Face & & & & & & & & & 40.10.II. & M. sympodialis \\
\hline 3. & & & Back & & & & & & & & & 40.10.IV. & M. sympodialis \\
\hline 4. & MP & & Head & $\mathrm{F}$ & 28 & 31 & $\mathrm{R}$ & 23 & Topical; sys: & Positive & Rhinoconjunctivitis & 8.11.І. & M. sympodialis \\
\hline 5. & & & Chest & & & & & & ninics & & & 8.11.III. & M. sympodialis + C. $d^{*}$ \\
\hline 6. & & & Back & & & & & & & & & 8.11.IV. & M. sympodialis \\
\hline 7. & DJ & & Chest & M & 29 & 34.6 & $\mathrm{R}$ & 29 & Topical; sys: & Positive & Rhinoconjunctivitis & 27.10.|II. & M. sympodialis \\
\hline 8. & & & Back & & & & & & & & & 27.10.IV. & M. sympodialis \\
\hline 9. & JW & & Chest & $\mathrm{F}$ & 22 & 10.2 & $\mathrm{R}$ & 22 & Topical; sys: & Positive & No & 7.11.III. & M. sympodialis \\
\hline 10. & & & Back & & & & & & & & & 7.11.IV. & M. sympodialis \\
\hline 11. & $\mathrm{MB}$ & & Back & M & 22 & 39.4 & $\mathrm{R}$ & 22 & $\begin{array}{l}\text { Topical; sys: } \\
\text { antihistaminics }\end{array}$ & Negative & & 25.10.IV. & M. sympodialis \\
\hline 12. & EP & & Back & $\mathrm{F}$ & 31 & 10.2 & $\mathrm{R}$ & 31 & $\begin{array}{l}\text { Topical; sys: } \\
\text { antihistaminics }\end{array}$ & Negative & Vitiligo & 17.10.IV. & M. sympodialis \\
\hline 13. & BT & PS & Head & $\mathrm{F}$ & 50 & 8.2 & $\mathrm{R}$ & 20 & Topical; sys: CyA & Positive & No & 10.11.І. & M. sympodialis \\
\hline 14. & & & Face & & & & & & & & & 10.11..I. & M. sympodialis + A. p..$^{* *}$ \\
\hline 15. & & & Chest & & & & & & & & & $\begin{array}{l}10.11 \\
\text { IIIA. }\end{array}$ & M. furfur \\
\hline 16. & & & Back & & & & & & & & & 10.11.IV. & M. sympodialis \\
\hline 17. & $\mathrm{BH}$ & & Face & $\mathrm{F}$ & 44 & 10 & $\mathrm{R}$ & 15 & Topical & Negative & No & 45.08.II. & M. furfur \\
\hline 18. & & & Chest & & & & & & & & & 45.08.III. & $\begin{array}{l}\text { M. furfur }+M \text {. } \\
\text { sympodialis }\end{array}$ \\
\hline 19. & SK & & Back & M & 38 & 3.6 & $\mathrm{R}$ & 5 & Topical; sys: CS & Negative & No & 20.09.IV. & $\begin{array}{l}\text { M. furfur }+M \text {. } \\
\text { sympodialis }\end{array}$ \\
\hline 20. & EN & & Back & $\mathrm{F}$ & 31 & 6.6 & $\mathrm{R}$ & 5 & Topical & Negative & No & 17.09.IV. & M. sympodialis \\
\hline 21. & KK & & Face & M & 23 & 11.2 & $\mathrm{R}$ & 12 & Topical; sys: CyA & Positive & No & 43.08.II. & M. furfur \\
\hline 22. & $\mathrm{MB}$ & & Back & $\mathrm{F}$ & 29 & 5.7 & $R$ & 15 & Topical & Positive & No & 6.11.IV. & M. sympodialis \\
\hline 23. & MT & Control & Head & $\mathrm{F}$ & 31 & & & & & & No & 1.11.IA. & M. globosa \\
\hline 24. & & & Face & & & & & & & & & $1.11 . \|$. & $\begin{array}{l}\text { M. globosa }+M \text {. } \\
\text { restricta }\end{array}$ \\
\hline 25. & & & Chest & & & & & & & & & 1.11.IIIA. & M. sympodialis \\
\hline 26. & & & Back & & & & & & & & & 1.11.IVA. & M. sympodialis \\
\hline 27. & $\mathrm{CM}$ & & Chest & M & 70 & & & & & & No & 69.09.III. & M. slooffiae \\
\hline
\end{tabular}


Table 1 Characteristics of 18 subjects under the study and microbiological details of $\mathbf{3 5}$ isolated Malassezia species (Continued)

28. Back

69.09.IV. M. slooffiae + M sympodialis

\begin{tabular}{|c|c|c|c|c|c|c|}
\hline 29. BP & Chest & M & 69 & No & 67.09.III. & M. sympodialis \\
\hline 30. & Back & & & & 67.09.IV. & M. sympodialis \\
\hline 31. PK & Chest & M & 27 & No & 68.09.|II. & M. sympodialis \\
\hline 32. & Back & & & & 68.09.IV. & M. sympodialis \\
\hline 33. MS & Chest & $\mathrm{F}$ & 28 & No & 2.11..II. & M. sympodialis \\
\hline 34. & Back & & & & 2.11.IV. & M. sympodialis \\
\hline 35. JP & Back & $\mathrm{F}$ & 31 & No & 12.09.IV. & M. sympodialis \\
\hline
\end{tabular}

35.

Three subject groups under investigation: (i) patients with atopic dermatitis (AD), (ii) patients with psoriasis (PS), and (iii) healthy volunteers (control).

The numbers represent the SCORAD index values in AD patients, or the PASI index values in psoriatic patients.

${ }^{e} \mathrm{R}$, recurrent.

${ }^{\text {T}}$ Topic treatment for AD patients included emolients, corticosteroids, tacrolimus, pimecrolimus, antibiotics, whereas topic treatment for psoriatic patients included corticosteroids, calcipotriol, tacrolimus, pimecrolimus, emollients; CS, corticosteroids; CyA: Cyclosporine A; sys., systemic.

${ }^{9}$ Based on direct interviewing of the patients.

${ }^{h}$ Final species identification results, based upon integration of conventional and molecular data. ${ }^{*}$ C. $d$., Cryptococcus diffluens; ${ }^{* *}$ A. p., Aureobasidium pullulans. 


\section{Sample collection}

From each patient, four samples originating from four different anatomical sites of the body, that is the scalp, face, chest (interclavicle region) and back (interscapular region) were collected by a standard swab method. A sterile cotton swab soaked with sterile saline was used to rub against the skin surface, with continuous rotation of the swab and over at least 15 seconds, and immediately streaked evenly onto modified Dixon's agar (mDA) medium.

\section{Culture conditions and yeast strains}

The yeasts were cultured on $\mathrm{mDA}$ plates at $32^{\circ} \mathrm{C}$, with growth being monitored every day for two weeks. The suspected colonies of Malassezia sp. were subcultured, by streaking onto $\mathrm{mDA}$ slants, and subjected to the identification procedures described hereafter. The cultures were maintained by weekly passaging on fresh mDA slants.

Apart from the Malassezia sp. strains isolated from clinical samples, six reference strains representing as many Malassezia species (Malassezia furfur CBS 6001; M. globosa CBS 7966; M. obtusa CBS 7876; M. slooffiae CBS 7956; M. restricta CBS 7877; M. sympodialis CBS 7222) and purchased from the CBS (Centraalbureau voor Schimmelcultures, Utrecht, The Netherlands) culture collection were included in the study.

\section{Drug susceptibility testing}

In vitro susceptibility testing was performed by using commercially available Neo-Sensitabs diffusion assays (Neo-Sensitabs, Rosco Diagnostica, Denmark), according to the instructions provided by the manufacturer and following the Clinical and Laboratory Standards Institute (CLSI) guidelines [46] with some modifications. Colonies from a seven-day yeast culture, grown on $\mathrm{mDA}$, were scraped off and suspended in sterile saline with sterile glass beads. The suspension was mixed vigorously for 30 seconds in a vortex mixer, and adjusted to a turbidity equivalent of a 5.0 McFarland standard. The so prepared inoculum was swabbed over the mDA plates. After allowing the plates to dry completely, Neo-Sensitabs tablets containing $50 \mu \mathrm{g}$ of ciclopirox (CPO), $25 \mu \mathrm{g}$ of fluconazole (FLZ), $15 \mu \mathrm{g}$ of ketoconazole (KTZ), $10 \mu \mathrm{g}$ of econazole (ECZ), $10 \mu \mathrm{g}$ of miconazole (MNZ), and $8 \mu \mathrm{g}$ of itraconazole (ITZ) were applied onto the surface and the plates were incubated at $32^{\circ} \mathrm{C}$, with reading taken after 48 and $72 \mathrm{~h}$. The zones of inhibition were measured at a point in which either there was prominent reduction of growth or no visible growth occurred. Since the interpretation of antifungal resistant/susceptible categories among the Malassezia species has not yet been established, interpretive criteria for the yeasts reported by the CLSI [46] and provided by the manufacturer of the Neo-Sensitabs were employed. Accordingly, resistance was assumed if the inhibition zone was less than $10 \mathrm{~mm}$ for ITZ, less than or equal to $11 \mathrm{~mm}$ for CPO, $\mathrm{ECZ}$, and $\mathrm{MNZ}$, less than or equal to $14 \mathrm{~mm}$ for FLZ, and less than or equal to $22 \mathrm{~mm}$ for KTZ.

To validate the performance of the Neo-Sensitabs drug susceptibility testing, two quality control (QC) strains were used: Pichia kudriavzevii (teleomorph of Candida krusei) DBVPG 7235 (corresponding to ATCC 6258) and Candida parapsilosis DBVPG 6150 (corresponding to ATCC 22019), from the Industrial Yeasts Collection DBVPG (Perugia, Italy).

All Malassezia strains were tested in duplicate. Also, the QC strains were assayed twice.

\section{DNA isolation}

Genomic DNA extraction was done from pure cultures. Briefly, a few yeast colonies were suspended in $200 \mu \mathrm{L}$ of TE buffer (10 mM Tris- $\mathrm{HCl}$ [pH 8.0], 1 mM EDTA) and subjected to 3 rounds of sonication (three sonication cycles of $15 \mathrm{~s}$ each separated by $15 \mathrm{~s}$ intervals) in ice water bath, at $20 \%$ amplitude in a Vibra Cell sonicator (Sonics \& Materials Inc., USA). The obtained homogenate was further processed with the Genomic Mini AX Yeast kit (A\&A Biotechnology, Poland) following the manufacturer's instructions.

\section{Species identification Identification by phenotypic methods}

All yeast cultures were identified to species level by using conventional mycological methods, including examination of colonial and microscopic morphologies (i.e. colonies' shape, texture, and colour, and cell size, shape and budding characteristics) as well as physiological and biochemical tests, including assimilation of Tween 20, 40, 60, and 80, assimilation of Cremophor EL, catalase reaction, cleavage of esculin, and growth at $37^{\circ} \mathrm{C}$. Phenotypic feature testing was performed essentially as described elsewhere [47], and the characteristics table of Malassezia spp. provided by Ashbee and Evans [48] served as the species identification key.

\section{Molecular analysis}

Molecular identification involved PCR-RFLP analysis along with sequence analysis of different nuclear loci within the rDNA operon of Malassezia spp., including the ITS1 and ITS2 regions and the D1 and D2 domains of the 26S rRNA gene.

\section{PCR-RFLP analysis}

Two PCR-RFLP assays, targeting the ITS2 region and partial $26 \mathrm{~S}$ rRNA gene, were performed, as described previously $[28,29]$, with slight modifications. Briefly, primers ITS3 (5'-GCATCGATGAAGAACGCAGC-3') and ITS4 (5'-TCCTCCGCTTATTGATATGC-3') were used to 
amplify the ITS2 region, whereas primers Malup (5'AGCGGAGGAAAAGAAACT-3') and Maldown (5'GCGCGAAGGTGTCCGAAG-3') were used to amplify the 26S rRNA gene fragment (Figure 1). PCR mixtures were prepared by using the TopTaq Master Mix kit (QIAGEN, Germany) in a total volume of $25 \mu \mathrm{L}$, containing $2 \times$ TopTaq Master Mix (final conc. $1 \times$; the mix contains $1.25 \mathrm{U}$ of Taq DNA polymerase, $200 \mu \mathrm{M}$ each deoxyucleoside triphosphate, and $1 \times$ PCR buffer with $1.5 \mathrm{mM} \mathrm{MgCl} 2$ ), $0.4 \mu \mathrm{M}$ each primer, and $1 \mu \mathrm{L}$ (ca. $10-$ $20 \mathrm{ng}$ ) of template DNA. The PCR conditions were as follows: $94^{\circ} \mathrm{C}$ for $3 \mathrm{~min}, 30$ cycles at $94^{\circ} \mathrm{C}$ for $30 \mathrm{~s}, 50^{\circ} \mathrm{C}$ for $30 \mathrm{~s}$, and $72^{\circ} \mathrm{C}$ for either $30 \mathrm{~s}$ (ITS2) or $50 \mathrm{~s}(26 \mathrm{~S}$ rDNA), and a final step at $72^{\circ} \mathrm{C}$ for $10 \mathrm{~min}$. After confirmation of the presence of the amplicons of correct sizes with gel electrophoresis, the purified PCR products of the ITS2 and 26S rDNA regions were subjected to RFLP analysis with AluI and HaeII enzymes, respectively. Restriction reactions were carried out in $20 \mu \mathrm{L}$ volumes containing $8 \mu \mathrm{L}$ (ca. $200 \mathrm{ng}$ ) of PCR product and 1 $\mathrm{U}$ of the restriction enzyme together with the appropriate reaction buffer (final conc. $1 \times$ ) at $37^{\circ} \mathrm{C}$ for $45 \mathrm{~min}$ (FastDigest restriction enzymes; Fermentas UAB, Lithuania). Restriction patterns were compared with those of reference Malassezia strains and virtual, species-specific patterns established in the original publications $[28,29]$.

\section{PCR-sequencing}

Sequencing of the ITS1 and ITS2 regions and the D1/ D2 domains of the 26S rRNA gene was performed, as reported earlier [26]. In short, primers V9 (5'TGCGTTGATTACGTCCCTGC-3') and RLR3R (5'GGTCCGTGTTTCAAGAC-3') amplified a fragment encompassing ITS1, the 5.8S rRNA gene, ITS2, and partial regions of the $18 \mathrm{~S}$ and $26 \mathrm{~S}$ rDNA (Figure 1).

The PCR was carried out in a $25-\mu \mathrm{L}$ reaction volume containing $2 \times$ TopTaq Master Mix (final conc. $1 \times$ ) (QIAGEN, Germany), $0.5 \mu \mathrm{M}$ each primer, and $1 \mu \mathrm{L}$ (ca. $20 \mathrm{ng}$ ) of template DNA. The thermal cycling profile was $94^{\circ} \mathrm{C}$ for $5 \mathrm{~min}, 30$ cycles at $94^{\circ} \mathrm{C}$ for $45 \mathrm{~s}, 56^{\circ} \mathrm{C}$ for $30 \mathrm{~s}$, and $72^{\circ} \mathrm{C}$ for $1.5 \mathrm{~min}$, and a final step at $72^{\circ} \mathrm{C}$ for $10 \mathrm{~min}$. The resulting amplicons were electrophoresed to verify the presence of a single product of the correct size, purified, and sequenced either directly or after cloning into a plasmid vector using the pGEM-T Easy Vector system (Promega, USA), according to the vendor's protocol, when initial sequence information showed the possible presence of two (or more) different species.

The primers used in the sequence reaction were ITS4 (5' ${ }^{\prime}$-TCCTCCGCTTATTGATATGC-3') and ITS5 (5'GGAAGTAAAAGTCGTAACAAGG-3') for analysis of the ITS1/ITS2, and NL1 (5'-GCATATCAATAAGCGGAGGAAAAG-3') and RLR3R for analysis of the D1/ D2 domains of the 26S rRNA gene (Figure 1).
Forward and reverse sequences were assembled and edited with ChromasPro ver. 1.7.1 (Technelysium, Australia) and the resulting consensus sequences were searched against the GenBank database of the National Center for Biotechnology Information (NCBI) using the BLASTN algorithm (http://blast.ncbi.nlm.nih.gov/).

Distance scores of up to $1.00 \%$ (99\% match) were used as a proxy for species identity, and the species giving the closest match was considered the correct identification.

The nucleotide sequences determined in the study were deposited in the GenBank database (NCBI) under the accession numbers listed in Table 2.

\section{Statistical analysis}

The Chi-square test and Fisher's exact test were used to evaluate the differences in the frequency and distribution of Malassezia species between the AD patients, PS patients, and healthy subjects. A $P$ value $<0.05$ was considered statistically significant.

\section{Ethics}

The study was approved by the Ethics Committee of the Jagiellonian University in Kraków. All the patients gave informed consent to participate in the study.

\section{Results}

A total of 35 Malassezia sp. cultures were obtained from clinical samples, with back being the most frequent site of isolation (16 cultures; $45.7 \%$ of all Malassezia cultures), followed by chest $(10 ; 28.6 \%)$, face $(5 ; 14.3 \%)$, and head $(4 ; 11.4 \%)$. Of 24 skin samples collected from each of the three subject groups, 13 (54.2\%), 12 (50\%), and 10 $(41.7 \%)$ gave positive culture in the control group, AD group, and PS group, respectively. The overall positive culture rate of the Malassezia yeasts from 4 different body sites of 18 patients under the study was $48.6 \%$ ( 35 positive samples out of 72 samples tested).

\section{Phenotypic identification}

Based on conventional, phenotypic methods, all 35 yeast cultures were initially separated into 5 different Malassezia species. There were recognized 19 (54.3\%) M. sympodialis, 7 (20\%) M. furfur, 5 (14.3\%) M. slooffiae, 2 (5.7\%) M. globosa, and 2 (5.7\%) M. obtusa isolates. Among the isolates from $\mathrm{AD}$ patients and healthy volunteers, $M$. sympodialis predominated and accounted for $66.7 \%(8 / 12)$ and $46.1 \%$ $(6 / 13)$ of the isolates, respectively. In both these groups there were isolates of other four (control group) or three (all but M. globosa) species (AD group). In psoriatic patient group, only two species, equally abundant, were identified, namely $M$. sympodialis and $M$. furfur. 


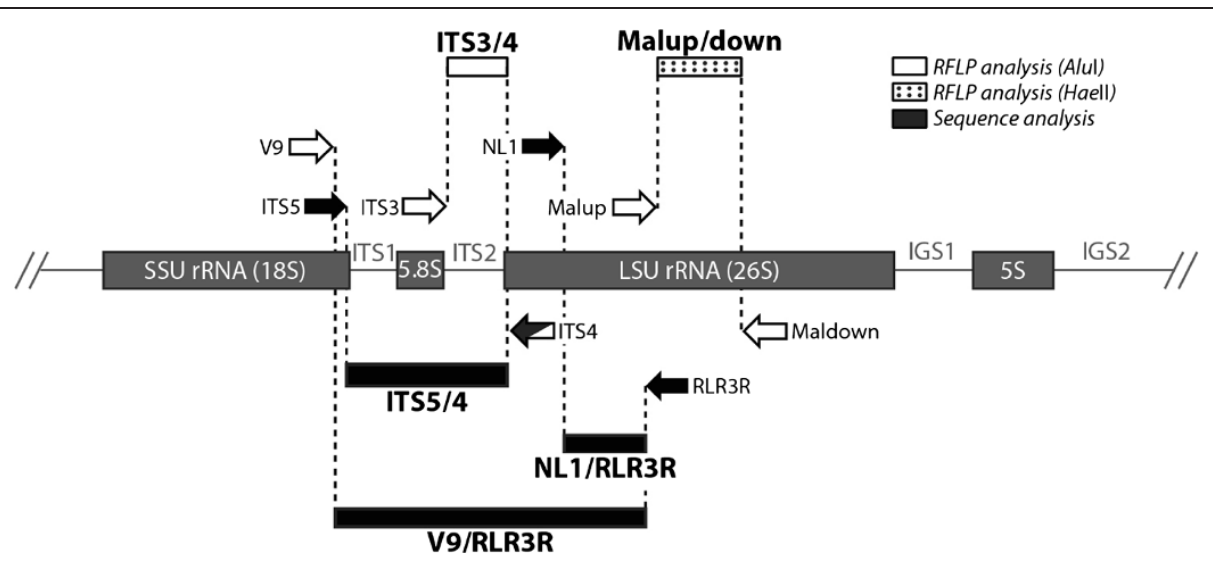

Figure 1 Schematic representation of the rDNA operon in Malassezia yeasts. The loci under analysis are depicted. Major rRNA genes are shown as grey boxes. Primers used for PCR amplification of the target DNA sequences and those used for sequencing are indicated as white and black block arrows, respectively. Loci analysed by PCR-RFLP or direct sequencing are shown as black or white rectangles, respectively, and are designated after the primers used for their amplification (or sequencing). LSU, large subunit (rRNA); SSU, small subunit (rRNA); IGS, intergenic spacer region; ITS, internal transcribed spacer.

\section{PCR-RFLP analysis}

PCR amplification of the partial $26 \mathrm{~S}$ rRNA gene produced, for all isolates, a single amplicon of the expected size of $c a .550 \mathrm{bp}$. Upon digestion of the amplified products with the HaeII restriction enzyme 4 different restriction patterns could be distinguished. Three of them matched exactly the HaeII restriction patterns predicted for $M$. sympodialis (26 isolates; $74.3 \%$ of all isolates), $M$. furfur or $M$. slooffiae $(6 ; 17.1 \%)$, and $M$. globosa or $M$. restricta (2; 5.7\%). For one isolate (20.09.IV.) a mixed HaeII restriction pattern was obtained, corresponding to M. sympodialis and M. furfur or M. slooffiae.

A single amplicon of $c a .400-500 \mathrm{bp}$ in size was generated by PCR amplification of the ITS2 region for all Malassezia isolates except one (20.09.IV.), for which two PCR products were visualized (one of $c a .400 \mathrm{bp}$ and another of $c a .500 \mathrm{bp}$ ). When the PCR products were digested with the AluI restriction enzyme 6 different restriction patterns were demonstrated, 4 of which corresponded to those expected for M. sympodialis (24 isolates; $68.6 \%$ of all isolates), M. furfur (4; 11.4\%), M. slooffiae (2; $5.7 \%)$, and $M$. globosa $(1 ; 2.9 \%)$. The restriction pattern of one isolate (1.11.II.) was a combination of those for M. globosa and $M$. restricta. The restriction patterns of 2 isolates (10.11.II.; 8.11.III.) contained a fragment characteristic of M. sympodialis, along with two additional fragments whose sizes did not correlate with the sizes of the AluI restriction fragments previously reported for Malassezia species. In case of one isolate, for which two PCR products were obtained, they were both purified by gel extraction and subjected to AluI digestion separately (20.09.IV.A/B). This resulted in 2 single restriction profiles, conforming to that of $M$. sympodialis and of $M$. furfur.

Based on the results from two PCR-RFLP assays, 31 $(88.6 \%)$ of the isolates tested could be separated into 4 distinct Malassezia species, namely, M. sympodialis (24 isolates; $68.6 \%$ of all isolates), $M$. furfur (4; 11.4\%), $M$. slooffiae (2; 5.7\%), and M. globosa (1;2.9\%). Two isolates were identified as a mixture of two different Malassezia species, that is M. sympodialis and M. furfur (20.09.IV.) and M. globosa and M. restricta (1.11.II.). Finally, 2 isolates (10.11.II.; 8.11.III.) appeared to represent M. sympodialis mixed with another unknown fungal species.

\section{PCR-sequence analysis}

The rDNA region containing the ITS1/ITS2 sequences and D1/D2 domains of the 26S rRNA was successfully amplified, for all isolates tested, resulting in a sole product of $c a .1,500 \mathrm{bp}$. The purified PCR products were used as templates in two independent sequencing reactions, targeting the ITS and D1/D2 loci, respectively. Upon ITS1/ITS2 sequence analysis, 33 (94.3\%) of the isolates tested, could be unambiguously identified at the species level. The consensus ITS sequences of those isolates shared $\geq 99 \%$ similarity with the sequences of previously characterized fungal species, as evidenced by the BLAST search of the GenBank database. Twenty-four (68.6\% of all isolates) isolates had a $100 \%$ similarity with the sequence of M. sympodialis. Four (11.4\%) isolates showed $100 \%$ sequence identity with $M$. furfur, and 2 (5.7\%) isolates showed 99\% sequence similarity with $M$. slooffiae. The ITS1/ITS2 sequences of 2 isolates designated 8.11.III and 10.11.II., formerly identified as $M$. sympodialis (on PCR-RFLP analysis) showed a complete match (100\% identity) to the ITS1/ITS2 sequences of Cryptococcus diffluens and Aureobasidium proteae/pullulans), respectively. The results for those two isolates were consistent, even if sequencing was performed on PCR products from different PCR runs using DNA from three different isolations. Sequence analysis of the ITS 
Table 2 Species identification results obtained upon phenotypic testing and molecular typing of 35 Malassezia cultures

$\begin{array}{ll}\text { Strain } & \text { Species identification by means of } \\ \text { no. } & \begin{array}{l}\text { Phenotypic } \\ \text { methods }^{a}\end{array}\end{array}$

Final species methods PCR-RFLP

\begin{tabular}{llll}
\multicolumn{2}{l}{ PCR sequencing ${ }^{c}$} \\
$\begin{array}{llll}\text { ITS } & \text { Similarity with ITS } & \text { D1/D2 } & \text { Similarity with D1/ } \\
\text { accession } & \text { of [\%]: } & \begin{array}{l}\text { accession } \\
\text { no. }\end{array} & \text { D2 of [\%]: }\end{array}$ \\
\hline
\end{tabular}

identification $^{d}$

no.

1. 40.10.1. M. slooffiae M. sympodialis

2. 40.10.ll. M. slooffiae M. sympodialis

3. $\quad$ 40.10.IV. M. sympodialis M. sympodialis

4. 8.11.I. M. obtusa

M. sympodialis

5. 8.11.III. M. furfur

M. sympodialis

6. 8.11.IV. M. sympodialis M. sympodialis

7. 27.10.III. M. sympodialis M. sympodialis

8. 27.10.IV. M. sympodialis M. sympodialis

9. 7.11.III. M. sympodialis M. sympodialis

10. 7.11.IV. M. sympodialis M. Mympodialis

11. 25.10.IV. M. sympodialis M. Mympodialis

12. 17.10.IV. M. sympodialis M. sympodialis

13. 10.11.I. M. sympodialis M. sympodialis

14. 10.11.II. M. sympodialis M. sympodialis

15. 10.11.IIA. M. furfur M. furfur

16. 10.11.IV. M. Mympodialis M. sympodialis

17. 45.08.II. M. furfur $\quad$ M. furfur

18. 45.08.III. M. furfur $\quad$ M. furfur

19. 20.09.IV. M. furfur

M. furfur $+M$. sympodialis

20. 17.09.IV. M. sympodialis M. sympodialis

21. 43.08.II. M. furfur M. furfur

22. 6.11.IV. M. sympodialis M. sympodialis

23. $1.11 . \mathrm{I}$ M. globosa M. globosa

24. 1.11.II. M. globosa

M. globosa + M. restricta $\begin{array}{llll}\text { KC141968 } & \begin{array}{l}\text { M. sympodialis } \\ \text { MA } 73\end{array} & \text { 100\% } & \text { KC415092 }\end{array}$

KC141969 M. sympodialis 100\% KC415093 CBS 7222

KC141970

M. sympodialis CBS 7222

KC152895 M. sympodialis 100\% KC415085 CBS 7222

KC152904 C. diffluens CBS 100\% KC241877 160

KC152896 M. sympodialis $\quad 100 \% \quad$ KC415086 CBS 7222

KC141966

M. sympodialis MA 73

KC141967 M. sympodialis 100\% KC415096 MA 73

KC152893 M. sympodialis 100\% KC415083 CBS 7222

KC152894

M. sympodialis MA 73

KC119577 M. sympodialis 100\% KC415097 CBS 7222

KC119576 M. sympodialis 100\% KC415098 CBS 7222

KC152897 M. sympodialis CBS 7222

KC152905

A. pullulans CPC 13701

KC152897 M. furfur M235 100\% KC415088

KC152901 M. sympodialis 100\% KC415091 CBS 7222

KC141972

M. furfur M235

$100 \%$ KC415099

KC141973 M. sympodialis 100\% KC415100 CBS 7222

KC141965 M furfur M235 100\% KC415101

KC109788 M. sympodialis 100\% KC415102 MA 73

KC141971 M. furfur M235 100\% KC415103

KC152892 M. sympodialis $100 \% \quad$ KC415082 MA 73

KC152884

M. globosa CBS 96\% KC415074 7966

KC152885

M. restricta MRE28
M. sympodialis IFM 48109

M. sympodialis IFM 48109

M. sympodialis IFM 48109

M. sympodialis IFM 48109

C. diffluens CBS $100 \% \quad$ M. sympodialis $+C$. d. $^{*}$ 6436

M. sympodialis IFM 48109

M. sympodialis IFM 48109

M. sympodialis IFM 48109

M. sympodialis IFM 48109

M. sympodialis IFM 48109

M. sympodialis IFM 48109

M. sympodialis IFM 48109

M. sympodialis IFM 48109

A. pullulans RA406

M. furfur VG Ig $\quad 99 \% \quad$ M. furfur 02

M. sympodialis IFM 48109

M. furfur VG Ig 02

M. sympodialis $\quad 99 \% \quad$ M. furfur + M. IFM $48109 \quad$ sympodialis

M. furfur VG Ig $\quad 99 \% \quad$ M. furfur $+M$. 02 sympodialis

M. sympodialis $\quad 100 \% \quad$ M. sympodialis IFM 48109

M. furfur VG Ig $\quad 100 \%$ M. furfur 02

M. sympodialis $\quad 100 \% \quad$ M. sympodialis IFM 48109

M. sympodialis IFM 48109

M. sympodialis IFM 48109
100\% M. globosa

100\% M. globosa + M restricta 
Table 2 Species identification results obtained upon phenotypic testing and molecular typing of 35 Malassezia cultures (Continued)

\begin{tabular}{|c|c|c|c|c|c|c|c|c|c|c|}
\hline 25. & 1.11.IIIA. & M. sympodialis & M. sympodialis & KC152886 & $\begin{array}{l}\text { M. sympodialis } \\
\text { MA } 73\end{array}$ & $100 \%$ & KC415076 & $\begin{array}{l}\text { M. sympodialis } \\
\text { IFM } 48109\end{array}$ & $100 \%$ & M. sympodialis \\
\hline 26. & 1.11.IVA. & M. furfur & M. sympodialis & KC152888 & $\begin{array}{l}\text { M. sympodialis } \\
\text { MA } 73\end{array}$ & $100 \%$ & KC415078 & $\begin{array}{l}\text { M. sympodialis } \\
\text { IFM } 48109\end{array}$ & $100 \%$ & M. sympodialis \\
\hline 27. & 69.09.III. & M. slooffiae & M. slooffiae & KC141978 & $\begin{array}{l}\text { M. slooffiae CBS } \\
7956\end{array}$ & $99 \%$ & KC415104 & $\begin{array}{l}\text { M. slooffiae } \\
\text { sc7LG }\end{array}$ & $99 \%$ & M. slooffiae \\
\hline 28. & 69.09.IV. & M. slooffiae & M. slooffiae & KC141979 & $\begin{array}{l}\text { M. slooffiae CBS } \\
7956\end{array}$ & $99 \%$ & KC415105 & $\begin{array}{l}\text { M. sympodialis } \\
\text { IFM } 48109\end{array}$ & $100 \%$ & $\begin{array}{l}\text { M. slooffiae }+M \text {. } \\
\text { sympodialis }\end{array}$ \\
\hline 29. & 67.09.III. & M. sympodialis & M. sympodialis & KC141974 & $\begin{array}{l}\text { M. sympodialis } \\
\text { CBS } 7222\end{array}$ & $100 \%$ & KC415106 & $\begin{array}{l}\text { M. sympodialis } \\
\text { IFM } 48109\end{array}$ & $100 \%$ & M. sympodialis \\
\hline 30. & 67.09.IV. & M. slooffiae & M. sympodialis & KC141975 & $\begin{array}{l}\text { M. sympodialis } \\
\text { CBS } 7222\end{array}$ & $100 \%$ & KC415107 & $\begin{array}{l}\text { M. sympodialis } \\
\text { IFM } 48109\end{array}$ & $100 \%$ & M. sympodialis \\
\hline 31. & 68.09.III. & M. sympodialis & M. sympodialis & KC141976 & $\begin{array}{l}\text { M. sympodialis } \\
\text { CBS } 7222\end{array}$ & $100 \%$ & KC415108 & $\begin{array}{l}\text { M. sympodialis } \\
\text { IFM } 48109\end{array}$ & $100 \%$ & M. sympodialis \\
\hline 32. & 68.09.IV. & M. sympodialis & M. sympodialis & KC141977 & $\begin{array}{l}\text { M. sympodialis } \\
\text { CBS } 7222\end{array}$ & $100 \%$ & KC415109 & $\begin{array}{l}\text { M. sympodialis } \\
\text { IFM } 48109\end{array}$ & $100 \%$ & M. sympodialis \\
\hline 33. & 2.11.III. & M. sympodialis & M. sympodialis & KC152890 & $\begin{array}{l}\text { M. sympodialis } \\
\text { MA } 73\end{array}$ & $100 \%$ & KC415080 & $\begin{array}{l}\text { M. sympodialis } \\
\text { IFM } 48109\end{array}$ & $100 \%$ & M. sympodialis \\
\hline 34. & 2.11.IV. & M. obtusa & M. sympodialis & KC152891 & $\begin{array}{l}\text { M. sympodialis } \\
\text { MA } 73\end{array}$ & $100 \%$ & KC415081 & $\begin{array}{l}\text { M. sympodialis } \\
\text { IFM } 48109\end{array}$ & $100 \%$ & M. sympodialis \\
\hline 35. & 12.09.IV. & M. sympodialis & M. sympodialis & JX915741 & $\begin{array}{l}\text { M. sympodialis } \\
\text { MA } 73\end{array}$ & $100 \%$ & KC415110 & $\begin{array}{l}\text { M. sympodialis } \\
\text { IFM } 48109\end{array}$ & $100 \%$ & M. sympodialis \\
\hline
\end{tabular}

\footnotetext{
Identification algorithm included macro- and microscopic examination of fungal colonies along with biochemical tests, as described in the Materials and Methods section.

${ }^{b}$ Based on two PCR-RFLP assays (i. e. with Alul and Haell restriction endonucleases).

${ }^{c}$ Results of BLAST search of GenBank (http://blast.ncbi.nlm.nih.gov/); The ITS and D1/D2 accession numbers are those under which the respective sequences determined in this study can be found in the GenBank; Percentage similarities with ITS or D1/D2 sequences deposited in the GenBank are given.

${ }^{d}$ Based on combined molecular methods results; ${ }^{*}$ C. d., Cryptococcus diffluens; ${ }^{* *}$ A. p., Aureobasidium pullulans.
}

regions from one isolate (1.11.II.), identified as a mixture of M. globosa and M. restricta by PCR-RFLP analysis, was informative only after subcloning of the PCR product into the pGEM-T plasmid. Although several recombinants were examined, each time the ITS sequence homologous (99\% identity) to that of $M$. restricta was resolved. Interestingly, when applying the same procedure (i. e. sequence analysis from the pGEM-T vector) to the second isolate (20.09.IV.) that was identified as consisting of two different Malassezia species (M. furfur and $M$. sympodialis), only a sequence with $100 \%$ similarity with that of $M$. furfur could be revealed. Two isolates designated 2.11.III. and 1.11.IA. yielded ITS1/ITS2 sequences with $<99 \%$ similarity with the closest sequence in the GenBank database; the former gave the closest sequence match to M. sympodialis, whereas the latter - to M. globosa, at a similarity level of $97 \%$ and $96 \%$, respectively (Table 2).

Sequence analysis of partial 26S rRNA gene allowed clear species discrimination of all isolates tested. The sequences of 33 (94.3\%) isolates displayed $\geq 99 \%$ sequence identity to 4 Malassezia species strains, namely M. sympodialis (26 isolates; $74.3 \%$ of all isolates), M. furfur (4; $11.4 \%)$, M. globosa (2; 5.7\%), and M. slooffiae (1; 2.9\%). Finally, two isolates had a perfect match $(100 \%$ sequence identity), one for $C$. diffluens, and the other for $A$. pullulans.

The results from the sequence analysis of the D1/D2 and ITS loci were almost entirely concordant, with the concordance rate, calculated as percent agreement between paired results, of $94.3 \%$ (33/35 cases). The only discrepant results were from 2 isolates designated 69.09. IV. and 1.11.II., identified by D1/D2 sequencing as $M$. sympodialis and M. globosa, respectively. Whereas the former isolate had previously been identified (both by PCR-RFLP analysis and ITS sequencing) as M. slooffiae, the latter had initially been recognized as a mixture of M. globosa and M. restricta (upon PCR-RFLP analysis), with the presence of only $M$. restricta confirmed by ITS sequencing. Based on the combined ITS and D1/D2 sequence analysis, those 2 isolates were considered to represent mixtures of two Malassezia species, that is $M$. slooffiae and M. sympodialis (69.09.IV.) and M. globosa and $M$. restricta (1.11.II.).

\section{Comparison of PCR-RFLP analysis and PCR-sequencing analysis}

Concordance of the species identification results by using PCR-RFLP analysis and PCR-sequencing analysis was $85.7 \%$ (30/35 cases). Two isolates identified, upon 
PCR-RFLP analysis, as $M$. sympodialis (8.11.III.; 10.11. II.), were identified as $C$. diffluens (8.11.III.) and A. pullulans (10.11.II.) with PCR-sequencing. Another 2 isolates initially recognized as $M$. furfur (45.08.III.) and $M$. slooffiae (69.09.IV.) were re-identified as $M$. sympodialis and a mixture of M. slooffiae and M. sympodialis, accordingly. For one isolate (20.09.IV.) being a mixture of $M$. furfur and M. sympodialis, as demonstrated by PCRRFLP, only the presence of $M$. furfur was confirmed by sequence analysis.

\section{Comparison of phenotypic and molecular methods}

The results of phenotypic and molecular identification methods showed a concordance rate of $65.7 \%$ (23/35 cases). Twelve (34.3\%) isolates produced discrepant results. These included 6 M. sympodialis isolates, which by phenotypic methods had initially been identified as $M$. slooffiae (in 3 cases), M. obtusa (2 cases), and M. furfur (one case), as well as 6 mixed-species isolates. Of the latter, morphological and biochemical tests correctly identified one of 2 co-occurring species in 5 cases. One isolate recognized as a mixture of $M$. sympodialis and $C$. diffluens had previously been identified as M. furfur, based on the physiological testing.

Overall, among the isolates under investigation, 29 $(82.9 \%)$ were identified as homogenous species, namely M. sympodialis (24; 68.6\%), M. furfur (3; 8.6\%), M. globosa $(1 ; 2.9 \%)$, and $M$. slooffiae $(1 ; 2.9 \%)$. The remaining $6(17.1 \%)$ isolates were demonstrated heterogeneous, being mixtures of two species; 2 isolates consisted of $M$. furfur and M. sympodialis, (20.09.IV.; 45.08.III.), one isolate contained M. sympodialis and M. slooffiae (69.09. IV.), and the other one M. globosa and M. restricta (1.11.II.). Two isolates were mixtures of $M$. sympodialis and a non-Malassezia species, that is either $C$. diffluens (8.11.III.) or A pullulans (10.11.II.).

\section{Drug susceptibility testing}

Evaluation of drug susceptibility of Malassezia spp. to 6 antifungal drugs was conducted on 19 isolates representing all Malassezia isolates cultured from 4 patients with $\mathrm{AD}, 4$ patients with PS, and 4 healthy volunteers, randomly selected within each subject groups. All isolates examined were found susceptible to all 6 antifungals tested (Table 3). Six (31.6\%) isolates showed intermediate susceptibility to at least one drug; 2 isolates (one of $M$. furfur (45.08.II.) and the other of M. sympodialis $(12.09 . I V)$.$) were intermediately susceptible to ECZ; one$ isolate, identified as a mixture of $M$. slooffiae and $M$. sympodialis (69.09.IV.) was intermediately susceptible to MNZ. Two isolates, identified as mixtures of $M$. furfur and M. sympodialis, and designated 45.08.III. and 20.09. IV. were intermediately susceptible to $2(\mathrm{KTZ}+\mathrm{ECZ})$ and $3(\mathrm{KTZ}+\mathrm{ECZ}+\mathrm{MNZ})$ drugs, respectively. A three- drug intermediate susceptible pattern $(\mathrm{KTZ}+\mathrm{ECZ}+$ MNZ) was also observed in one M. furfur isolate (43.08. II.). Overall, based on the inhibition zone diameter values, the more susceptible isolates included $M$. slooffiae and most of the M. sympodialis isolates, whereas the least susceptible isolates were represented by $M$. furfur and $M$. furfur co-cultured with $M$. sympodialis (Table 3).

\section{Distribution of Malassezia species}

The final species identification, based on the molecular data, was used to determine the frequency distribution of Malassezia species among different subject groups. Of the culture-positive samples from $\mathrm{AD}$ patients, all yielded $M$. sympodialis isolates. These were homogeneous cultures in all cases, except one, where a mixed culture of $M$. sympodialis and C. diffluens was obtained. Among the PS patients, 2 Malassezia species were identified, with $M$. sympodialis having been isolated from 7 (out of 9) samples of 5 (out of 6) patients, and M. furfur from 5 samples of 4 patients. Those 2 species co-occurred in 2 samples from 2 different patients. A specimen from one psoriatic patient yielded a co-culture of $M$. sympodialis and A. pullulans. In the control group M. sympodialis was the most frequently observed, having been isolated from a total of 10 (out of 13) skin samples of all healthy subjects, including every sample of 4 of them. Malassezia globosa and M. slooffiae were isolated from 2 samples of single subjects either alone or in combination with $M$. restricta and $M$. sympodialis, respectively.

Overall, $M$. sympodialis was the predominant species in all 3 subject groups, having been cultured from a total of $29(82.9 \%)$ skin samples collected from all subjects under the study except one PS patient. The second most common species was $M$. furfur, recovered from 5 specimens of 4 PS patients. Malassezia globosa and M. slooffiae were isolated from 2 samples, each, originating from 2 normal individuals. Two non-Malassezia species, namely $C$. diffluens and $A$. pullulans, both co-occurring with $M$. sympodialis, were recovered from a patient with $\mathrm{AD}$ and a patient with PS, respectively.

Statistical analysis of the data showed that the only significant association was that isolation of $M$. sympodialis alone was more frequent among $\mathrm{AD}$ patients and healthy volunteers, as opposed to PS patients, for whom isolation of other Malassezia and non-Malassezia species, either alone or mixed (also with $M$. sympodialis) was reported $(P<0.03)$.

\section{Discussion}

Although several Malassezia species have been associated with various dermatological diseases, the exact pathological role of individual species remains obscured. An essential and still open question is whether there 
Table 3 Results of drug susceptibility testing of 19 Malassezia sp. isolates, as determined by Neo-Sensitabs assay

\begin{tabular}{|c|c|c|c|c|c|c|c|c|c|c|c|c|}
\hline \multirow[t]{3}{*}{ Malassezia sp. (no.) } & \multicolumn{12}{|c|}{ Antifungal drug $^{a}$} \\
\hline & \multicolumn{2}{|l|}{$\mathrm{CPO}$} & \multicolumn{2}{|l|}{ FLZ } & \multicolumn{2}{|l|}{$\mathrm{KTZ}$} & \multicolumn{2}{|l|}{ ITZ } & \multicolumn{2}{|l|}{$\mathrm{ECZ}$} & \multicolumn{2}{|l|}{ MNZ } \\
\hline & $\begin{array}{l}\text { Zone } \\
{[\mathrm{mm}]^{b}}\end{array}$ & $\begin{array}{l}\text { Cat. } \\
\text { (no.) }\end{array}$ & $\begin{array}{l}\text { Zone } \\
{[\mathrm{mm}]}\end{array}$ & $\begin{array}{l}\text { Cat. } \\
\text { (no.) }\end{array}$ & $\begin{array}{l}\text { Zone } \\
{[\mathrm{mm}]}\end{array}$ & $\begin{array}{l}\text { Cat. } \\
\text { (no.) }\end{array}$ & $\begin{array}{l}\text { Zone } \\
{[\mathrm{mm}]}\end{array}$ & $\begin{array}{l}\text { Cat. } \\
\text { (no.) }\end{array}$ & $\begin{array}{l}\text { Zone } \\
{[\mathrm{mm}]}\end{array}$ & $\begin{array}{l}\text { Cat. } \\
\text { (no.) }\end{array}$ & $\begin{array}{l}\text { Zone } \\
{[\mathrm{mm}]}\end{array}$ & $\begin{array}{l}\text { Cat. } \\
\text { (no.) }\end{array}$ \\
\hline \multirow[t]{2}{*}{ M. sympodialis (13) } & 28 & $S(13)$ & 43 & $S(13)$ & 33.9 & $S(13)$ & 36.5 & $S(13)$ & 24.5 & $S(12)$ & 26.5 & S (13) \\
\hline & & & & & & & & & 17 & I (1) & & \\
\hline \multirow[t]{2}{*}{ M. furfur (2) } & 23 & $S(2)$ & 36 & $S(2)$ & 30 & $S(1)$ & 29 & $S(2)$ & 15.5 & I (2) & 20 & $S(1)$ \\
\hline & & & & & 25 & I (1) & & & & & 17 & I (1) \\
\hline \multirow{2}{*}{$\begin{array}{l}\text { M. furfur }+M \text {. } \\
\text { sympodialis (2) }\end{array}$} & 22.5 & $S(2)$ & 39 & $S(2)$ & 25.5 & I (2) & 28.5 & $S(2)$ & 14.5 & I (2) & 20 & $S(1)$ \\
\hline & & & & & & & & & & & 15 & I (1) \\
\hline M. slooffiae (1) & 30 & $S(1)$ & 45 & $S(1)$ & 35 & $S(1)$ & 45 & $S(1)$ & 30 & $S(1)$ & 20 & $S(1)$ \\
\hline $\begin{array}{l}\text { M. slooffiae }+M \text {. } \\
\text { sympodialis (1) }\end{array}$ & 30 & $S(1)$ & 40 & $S(1)$ & 40 & $S(1)$ & 40 & $S(1)$ & 30 & $S(1)$ & 16.5 & I (1) \\
\hline
\end{tabular}

${ }^{a} \mathrm{CPO}$, ciclopirox; FLZ, fluconazole; KTZ, ketoconazole; ITZ, itraconazole; ECZ, econazole; MNZ, miconazole; number of isolates are given in brackets.

${ }^{b}$ Inhibition zone diameter mean value $[\mathrm{mm}]$ (each isolated was tested twice).

'S usceptibility categorization ( $\mathrm{S}$, susceptible; I, intermediate; $R$, resistant) based on the following criteria: CPO, ECZ, MNZ: S, $\geq 20 ; \mathrm{I}, 12-19 ; \mathrm{R}, \leq 11 ; \mathrm{FLZ}$ : $\mathrm{S}, \geq 22$;

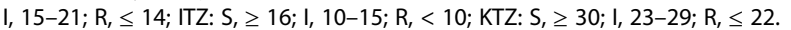

exists a relationship between particular Malassezia species and various skin disorders. Other clinical questions to be resolved include whether any of the Malassezia species preferentially occupies certain sites of the body, whether there are any differences in the distribution of the yeasts between lesioned and normal-appearing skin of patients, between adult and children, or between patients and healthy individuals, and finally whether there is variation in the prevalence of Malassezia species depending on gender, age, or geographical origin of the human host. There are now a growing number of works addressing these issues. For instance, studies of the Malassezia microbiota in healthy individuals consistently indicated M. globosa and M. restricta as the predominant species, with a combined detection rate of over $50 \%$ (in most of the studies) [7,31,32,34,35,49-51]. Whereas the involvement of the Malassezia species in SD and PV has been quite well recognized [35,50,52-58], the clinical role of these fungi in AD and PS is still controversial. The Malassezia yeasts are currently considered as contributory factors to the induction and exacerbation of both these conditions. The present study was to determine the composition of Malassezia microbiota on the skin of patients with AD and PS, and healthy volunteers from Poland. The choice of the study population was driven by two facts. First, there are much less data on the Malassezia microflora in AD and PS, than in other Malassezia-related diseases (i.e. PV, and SD). Second, $\mathrm{AD}$ and PS are the two most common chronic skin diseases, whose incidence has been on the rise in recent years in Poland. Among the Polish population, the prevalence of $\mathrm{AD}$ is around $1.4 \%$ in adults, and thrice as much $(4.7 \%)$ in children aged between 3 to 16 years (but up to $32 \%$ in infants and young children, that is aged between $0-6$ years) $[59,60]$. Psoriasis, on the other hand, is estimated to affect up to 1 million people in Poland ( $c a$. $2.6 \%$ of general population) [61].

The Malassezia yeasts were cultured from almost half (48.6\%) of the harvested skin samples, with the back being most heavily colonized body site, accounting for ca. $46 \%$ of the Malassezia cultures. The predominant Malassezia species in two clinical groups and the healthy control group was $M$. sympodialis. The recovery rate for this species among AD patients, PS patients, and healthy subjects was $100 \%, 70 \%$, and $76.9 \%$, respectively, and the overall recovery rate for M. sympodialis was $82.9 \%$. The finding of such a high prevalence of $M$. sympodialis was rather unexpected, since other Malassezia species have usually been much more abundant in all three aforementioned groups, as reported by other authors. In a study of Nakabayashi et al., M. sympodialis was only the third most common species in lesional skin of AD Japanese patients (7\% of samples), following M. furfur (21\%), and M. globosa (14\%) [50]. In a study from Sweden, M. sympodialis was absent from lesional sites of AD patients, whereas other Malassezia species (i. e. M. globosa, M. obtusa, M. restricta, and M. slooffiae) occurred at low rates of 3-11\% [62]. Two further studies that used culture-independent, DNA-based methods for the detection of Malassezia species, showed M. globosa and M. restricta as the predominant species in $\mathrm{AD}$. They were detected at frequencies ranging from $87.5 \%$ to $100 \%$, while $M$. sympodialis at $40.6 \%$ and $58.3 \%$ [35,51]. However, in a Canadian study of Gupta et al., it was $M$. sympodialis that predominated in $\mathrm{AD}$ patients, with a detection rate of 51.5\% [53]. Likewise, M. sympodialis was the dominant species among Korean AD patients, yet the isolation rate was low (16.3\%) [33]. Among very few reports on the prevalence and species composition of Malassezia yeasts in PS patients, two were almost completely negative for the presence of $M$. sympodialis; in 
a study from Bosnia and Herzegovina, the predominant species in PS patients was M. globosa (55\%) followed by M. slooffiae (17\%) and M. restricta (10\%) [63], while in a study from Iran, $M$. globosa, as the commonest species in PS (47\%), was followed by $M$. furfur (39\%) and M. restricta (11\%) [64]. Similar data were obtained from a Japanese, culture-independent study of Takahata et al., who found M. globosa and M. restricta as the sole two Malassezia species in psoriatic scale samples, with similarly high detection frequencies of $98 \%$ and $92 \%$, respectively [38]. However, in another study from Japan, as well as in a Canadian, culture-based study, $M$. sympodialis was found the third (50\%), after $M$. restricta (91\%) and M. globosa (68\%) or the second (31\%), after M. globosa (58\%) most frequently isolated Malassezia species from psoriatic lesions $[53,65]$. As for the healthy skin, none of the hitherto performed studies have shown the predominance of $M$. sympodialis, as that seen in the present work. This species has usually ranked third in overall abundance among Malassezia species colonizing normal human skin, with the detection rate spanned from $10 \%$ to ca. $40 \%$ $[7,31,32,35,50]$. Two major components of the Malassezia biota of healthy individuals, that is $M$. globosa and $M$. restricta were seriously underrepresented in the current study, with an overall isolation rate of $15.4 \%$ and $7.7 \%$, respectively. The disparities between the studies, as discussed above, in frequencies of Malassezia species isolations from different dermatological affections and body sites may be attributable to several factors, including geographical and ethnic origin, clinical and demographic characteristics and even lifestyle habits of the subjects under the study, but also certain methodological issues, such as the use of different sampling techniques (swabbing, scraping) or culture media (modified Dixon agar, Leeming-Notman agar). However, the distribution of Malassezia species is probably most influenced by a method used for species identification. Although the traditional identification schemes, based on morphological characteristics and biochemical activities, are in many clinical laboratories the only diagnostic methods available, they suffer from apparent limitations. Phenotypic tests are time-consuming, labour-intensive and often produce variable or inconclusive results, especially for newly described species; the final result relies on subjective interpretation by a laboratory expert. These methods are thus successively being complemented or replaced by DNA-based molecular techniques, of which PCR-RFLP analysis and PCR sequencing have most extensively been used [18,26,29-34,39-41]. Conceptually and technically PCR sequencing is the simplest. It is also the fastest and the most specific identification approach. An important advantage of DNA sequencing over PCR-RFLP is that the latter often involves a lengthy and laborious analysis of complex banding patterns, not always leading to a conclusive result. Moreover, DNA sequencing possesses a much higher discriminatory capacity, allowing intraspecies polymorphisms to be revealed. Some authors have already reported on the rDNA sequence heterogeneity within various Malassezia species, proving the existence of several individual genotypes within the species $[26,39,40]$. The intra-specific genetic diversity was also evidenced in this study. Two types of ITS sequences for $M$. sympodialis and two types of D1/2 sequences for M. globosa were demonstrated. Given the ability of DNA sequencing for strain typing and its potential use in phylogenetic and population genetics studies, along with the costs of sequencing rapidly plummeting, the method may soon become an integral part not only of a species identification algorithm but also of a routine epidemiological investigation.

The phenotypic and molecular identification results were discordant in $c a .35 \%$ of cases (12/35). The reason for this might either be the misidentification or the cooccurrence of different Malassezia species in one culture. The latter explanation is even more likely, as in the third of the discrepant cases, molecular methods did not invalidate the presence of a species identified by conventional phenotypic approach but only uncovered another, co-occurring Malassezia species. This in turn relates to the fact that the establishment of an axenic culture of a Malassezia species, uncontaminated by other Malassezia and non-Malassezia yeasts is rather challenging. A mixture of Malassezia species may not only be present in a clinical sample but even in a seemingly pure single colony on a culture medium. The co-isolation of two Malassezia species from the same specimen was recorded in $4(11.4 \%)$ cases evaluated in this study. A higher prevalence of mixed Malassezia cultures was reported by other authors. For instance, in a Korean study of Lee et al., 15\% of SD patients and 21\% of healthy volunteers showed co-colonization of two or more Malassezia species [34]. In two European studies, M. globosa, the most commonly observed species, was associated in culture with other Malassezia species in $18 \%$ of PV patients from Greece [52] and 40\% of PV patients from Spain [55]. Interestingly, in two cases in this study, $M$. sympodialis was co-cultured with a non-Malassezia species, namely Cryptococcus diffluens in an AD patient and Aureobasidium pullulans in a PS patient. Finding of $C$. diffluens on AD-affected skin is perfectly in line with previous research demonstrating this species to be a frequent colonizer of the skin surface of AD patients [66]. As for A. pullulans, it is a ubiquitous dematiaceous fungus that has emerged as an opportunistic human pathogen, especially among immunocompromised patients; it is a frequently isolated skin contaminant but rarely a causative agent of fungemia, systemic infections and abscesses in different viscera [67]. The discordance between phenotypic and molecular identification may also 
relate to the growth rate of different Malassezia species. It means that in a mixed culture, the fast-growing species, such as $M$. sympodialis may conceal the presence of the slow growers, such as $M$. globosa, M. restrica, or M. obtusa. This is also a possible explanation for the overall high frequency of $M$. sympodialis isolations in this study. Against this possibility is the fact that always a selected single separated colony from a primary culture served as an inoculum for the culture used for species identification tests. The six mixed-species cultures represent the only cases in which a primary culture colony already contained a mixture of distinct yeast species. Nevertheless, it seems that a molecular-based but cultureindependent method would serve as a more accurate and reliable approach for the assessment of the diversity of Malassezia microbiota [28,35,38,51]. The use of culturebased approach for characterizing Malassezia communities from skin samples posed a limitation to the present study. Due to the fastidious nature of Malassezia fungi and difficulties in culture arising therefrom, the obtained results may understate the size and complexity (species structure) of the Malassezia microbiota.

Culture-based methods essentially select for those species that readily grow under the typical nutritional and physiological conditions supported by commonly used artificial media. These species may not represent the most abundant or influential organisms within a given locality [68].

There is a paucity of reports on drug resistance in Malassezia spp., and this mainly stems from the lack of a standardized protocol for Malassezia susceptibility testing. The observed variability of the results from laboratory to laboratory precludes any association of in vitro and in vivo responses of Malassezia yeasts to antifungals. In this study, the Neo-Sensitabs tablet diffusion assay was employed to test the susceptibilities of selected Malassezia strains to six drugs most widely used in the treatment of Malassezia infections, that is the azoles (FLZ, ECZ, ITZ, KTZ, and $\mathrm{MNZ}$ ) and cyclopiroxolamine (CPO). All the analysed isolates were susceptible to those compounds, albeit the triazoles (FLZ and ITZ) and CPO were found to be more active than the azole derivatives (ECZ, MNZ, and KTZ). Noteworthy, strains of $M$. furfur generally appeared less susceptible than strains of $M$. slooffiae or M. sympodialis, indicating that certain Malassezia species develop mechanisms of drug tolerance more easily than other species do. Some variations between different Malassezia species in the susceptibilities to antifungal agents were also recorded by other authors [69,70]. Although the molecular bases of drug resistance in Malassezia fungi are largely unknown, there is an optimism that this will change now with an increasing body of data from the whole genome sequencing projects [71,72]. Recently, Kim et al. have demonstrated that genetic alterations in the amino acid sequence of a putative lanosterol 14 $\alpha$-demethylase (CYP51) from M. globosa may be responsible for resistance to azoles by blocking substrate access channels of the enzyme [73].

\section{Conclusions}

To conclude, this study provides an important insight into the species composition of Malassezia microbiota in human skin. The most important findings can be summarized in three points. First, M. sympodialis was the predominant species in both normal and pathologic (ADand PS-affected) skin. Furthermore, AD patients yielded exclusively $M$. sympodialis isolates, whereas isolates of $M$. furfur were observed only in PS patients. Whether this mirrors any predilection of particular Malassezia species for certain clinical conditions, and whether the overall dominance of $M$. sympodialis reflects geographical specificity needs to be evaluated on a much larger scale. Second, although the overall concordance between phenotypic and molecular methods was quite high (65\%), with the discordant results being rather due to the presence of multiple species in a single culture (co-colonization) than true misidentification, for the identification of Malassezia species, molecular typing approach is preferred, as its results are more reliable and straightforward. Third, all Malasse$z i a$ isolates were susceptible to cyclopiroxolamine and azole drugs, with $M$. furfur isolates being somewhat more drug tolerant than other Malassezia species.

\section{Abbreviations}

AD: Atopic dermatitis; AFLP: Amplified fragment length polymorphism; BSA: Body surface area; CHS2: Chitin synthase; CLSI: Clinical and Laboratory Standards Institute; CPO: Ciclopirox; DGGE: Denaturing gradient gel electrophoresis; ECZ: Econazole; FLZ: Fluconazole; ITS: Internal transcribed spacer; ITZ: Itraconazole; KTZ: Ketoconazole; MDA: Modified Dixon's agar; MEE: Multilocus enzyme electrophoresis; MNZ: Miconazole; NCBI: National Center for Biotechnology Information; PASI: Psoriasis area and severity; PCR-RFLP: PCR-based restriction fragment length polymorphism; PCRSSCP: PCR-based single strand confirmation polymorphism; PFGE: Pulsed-field gel electrophoresis; PS: Psoriasis; PV: Pityriasis versicolor; RPB1: RNA polymerase subunit 1; SCORAD: Severity scoring of atopic dermatitis; SD: Seborrheic dermatitis.

\section{Competing interests}

The authors declare that they have no competing interests.

\section{Authors' contributions}

TJ participated in the design of the study, supervised all experimental procedures, and wrote the entire manuscript. ER collected samples, performed drug susceptibility testing, participated in the design of the study and species identification. AZ performed the sequencing analyses. KR did the PCR-RFLP assays. AM and JB revised the manuscript critically for important intellectual content. All authors read and approved the final manuscript.

\section{Acknowledgements}

The authors are indebted to Asst. Prof. Aristea Velegraki (Department of Microbiology, Medical School, Aristotle University of Thessaloniki,

Thessaloniki, Greece) for her kind revision of the manuscript.

\section{Author details}

'Department of Applied Microbiology, Institute of Microbiology, Faculty of Biology, University of Warsaw, I. Miecznikowa 1, 02-096 Warsaw, Poland. 2Department of Mycology, Chair of Microbiology, Collegium Medicum, Jagiellonian University, Cracow, Poland. 
Received: 4 September 2013 Accepted: 1 March 2014

Published: 7 March 2014

\section{References}

1. Gao Z, Perez-Perez Gl, Chen Y, Blaser MJ: Quantitation of major human cutaneous bacterial and fungal populations. J Clin Microbiol 2010, 48:3575-3581.

2. Crespo-Erchiga V, Florencio VD: Malassezia yeasts and pityriasis versicolor. Curr Opin Infect Dis 2006, 19:139-147.

3. Hay RJ: Malassezia, dandruff and seborrhoeic dermatitis: an overview. Br J Dermatol 2011, 165:2-8.

4. Amado Y, Patiño-Uzcátegui A, de García MC C, Tabima J, Motta A, Cárdenas M, Bernal A, Restrepo S, Celis A: Seborrheic dermatitis: predisposing factors and ITS2 secondary structure for Malassezia phylogenic analysis. Med Mycol 2013, 51:868-875.

5. Kanda N, Tani K, Enomoto U, Nakai K, Watanabe S: The skin fungusinduced Th-1 and Th-2 related cytokine, chemokine and psostaglandin E2 production in peripheral blood mononuclear cells from patients with atopic dermatitis and psoriasis vulgaris. Clin Exp Allerg 2002, 32:1243-1250.

6. Baroni A, Paoletti I, Ruocco E, Agozzino M, Tufano MA, Donnarumma G: Possible role of Malassezia furfur in psoriasis: modulation of TGF-beta1, integrin, and HSP70 expression in human keratinocytes and in the skin of psoriasis-affected patients. J Cut Pathol 2004, 31:35-42.

7. Ko JH, Lee YW, Choe YB, Ahn KJ: Epidemiologic study of Malassezia yeasts in patients with Malassezia folliculitis by $26 \mathrm{~S}$ rDNA PCR-RFLP analysis. Ann Dermatol 2011, 23:177-184.

8. Zhao Y, Li L, Wang JJ, Kang KF, Zhang QQ: Cutaneous malasseziasis: four case reports of atypical dermatitis and onychomycosis caused by Malassezia. Int J Dermatol 2010, 49:141-145.

9. Bernier V, Weill FX, Hirigoyen V, Elleau C, Feyler A, Labrèze C, Sarlangue J, Chène G, Couprie B, Taïeb A: Skin colonization by Malassezia species in neonates. A prospective study and relationship with neonatal cephalic pustulosis. Arch Dermatol 2002, 138:215-218.

10. Ginarte M, Fabeiro JM, Toribio J: Confluent and reticulated papillomatosis (Gougerot-Carteaud) successfully treated with tacalcitol. J Dermatolog Treat 2002, 13:27-30.

11. Chryssanthou E, Broberger U, Petrini B: Malassezia pachydermatis fungaemia in a neonatal intensive care unit. Acta Paediatr 2001, 90:323-327.

12. Archer-Dubon C, Icaza-Chivez ME, Orozco-Topete R, Reyes E, Baez-Martinez R, Ponce de León S: An epidemic outbreak of Malassezia folliculitis in three adult patients in an intensive care unit: a previously unrecognized nosocomial infection. Int J Dermatol 1999, 38:453-456.

13. Guého E, Midgley G, Guillot J: The genus Malassezia with description of four new species. Antonie Van Leeuwenhoek 1996, 69:337-355.

14. Sugita T, Takashima M, Shinoda T, Suto H, Unno T, Tsuboi R, Ogawa $H$, Nishikawa A: New yeast species, Malassezia dermatis, isolated from patients with atopic dermatitis. J Clin Microbiol 2002, 40:1363-1367.

15. Sugita T, Takashima M, Kodama M, Tsuboi R, Nishikawa A: Description of a new yeast species, Malassezia japonica, and its detection in patients with atopic dermatitis and healthy subjects. J Clin Microbiol 2003, 41:4695-4699.

16. Sugita T, Tajima M, Takashima M, Amaya M, Saito M, Tsuboi R, Nishikawa A: A new yeast, Malassezia yamatoensis, isolated from a patient with seborrheic dermatitis, and its distribution in patients and healthy subjects. Microbiol Immunol 2004, 48:579-583.

17. Hirai A, Kano R, Makimura K, Duarte ER, Hamdan JS, Lachance MA, Yamaguchi $\mathrm{H}$, Hasegawa A: Malassezia nana sp. nov., a novel lipiddependent yeast species isolated from animals. Int I Syst Evol Microbiol 2004, 54:623-627.

18. Cabañes FJ, Theelen B, Castellá G, Boekhout T: Two new lipid-dependent Malassezia species from domestic animals. FEMS Yeast Res 2007, 7:1064-1076.

19. Cabañes FJ, Vega S, Castellá G: Malassezia cuniculi sp. nov., a novel yeast species isolated from rabbit skin. Med Mycol 2011, 49:40-48.

20. Casagrande BF, Flückiger S, Linder MT, Johansson C, Scheynius A, Crameri R, Schmid-Grendelmeier P: Sensitization to the yeast Malassezia sympodialis is specific for extrinsic and intrinsic atopic eczema. J Invest Dermatol 2006, 126(11):2414-2421.

21. Scheynius A, Johansson C, Buentke E, Zargari A, Linder MT: Atopic eczema/ dermatitis syndrome and Malassezia. Int Arch Allergy Immunol 2002, 127:161-169.
22. Guého E, Batra R, Boekhout T: The genus Malassezia Baillon (1889). In The Yeasts, a Taxonomic Study. 5th edition. Edited by Kurtzman CP, Fell JW, Boekhout T. Amsterdam: Elsevier; 2011:1807-1833.

23. Boekhout T, Kamp M, Guého E: Molecular typing of Malassezia species with PFGE and RAPD. Med Mycol 1998, 36:365-372.

24. Senczek D, Siesenop U, Böhm KH: Characterization of Malassezia species by means of phenotypic characteristics and detection of electrophoretic karyotypes by pulsed-field gel electrophoresis (PFGE). Mycoses 1999, 42:409-414.

25. Theelen B, Silvestri M, Guého E, van Belkum A, Boekhout T: Identification and typing of Malassezia yeasts using amplified fragment length polymorphism (AFLP), random amplified polymorphic DNA (RAPD) and denaturing gradient gel electrophoresis (DGGE). FEMS Yeast Res 2001, 1:79-86.

26. Gupta AK, Boekhout T, Theelen B, Summerbell R, Batra R: Identification and typing of Malassezia species by amplified fragment length polymorphism and sequence analyses of the internal transcribed spacer and large-subunit regions of ribosomal DNA. J Clin Microbiol 2004, 42:4253-4260

27. Midreuil F, Guillot J, Guého E, Renaud F, Mallié M, Bastide JM: Genetic diversity in the yeast species Malassezia pachydermatis analysed by multilocus enzyme electrophoresis. Int J Syst Bacteriol 1999, 49:1287-1294.

28. Gaitanis G, Velegraki A, Frangoulis E, Mitroussia A, Tsigonia A, Tzimogianni A, Katsambas A, Legakis NJ: Identification of Malassezia species from patient skin scales by PCR-RFLP. Clin Microbiol Infect 2002, 8:162-173.

29. Guillot J, Deville M, Berthelemy M, Provost F, Guého E: A single PCRrestriction endonuclease analysis for rapid identification of Malassezia species. Lett Appl Microbiol 2000, 31:400-403.

30. Mirhendi H, Makimura K, Zomorodian K, Yamada T, Sugita T, Yamaguchi H: A simple PCR-RFLP method for identification and differentiation of 11 Malassezia species. J Microbiol Methods 2005, 61:281-284.

31. Jang SJ, Lim SH, Ko JH, Oh BH, Kim SM, Song YC, Yim SM, Lee YW, Choe YB, Ahn KJ: The investigation on the distribution of Malassezia yeasts on the normal Korean skin by 26S rDNA PCR-RFLP. Ann Dermatol 2009, 21:18-26.

32. Oh BH, Song YC, Lee YW, Choe YB, Ahn KJ: Comparison of nested PCR and RFLP for identification and classification of Malassezia yeasts from healthy human skin. Ann Dermatol 2009, 21:352-357.

33. Yim SM, Kim JY, Ko JH, Lee YW, Choe YB, Ahn KJ: Molecular analysis of Malassezia microflora on the skin of the patients with atopic dermatitis. Ann Dermatol 2010, 22:41-47.

34. Lee YW, Byun HJ, Kim BJ, Kim DH, Lim YY, Lee JW, Kim MN, Kim D, Chun YJ, Mun SK, Kim CW, Kim SE, Hwang JS: Distribution of Malassezia species on the scalp in Korean seborrheic dermatitis patients. Ann Dermatol 2011, 23:156-161.

35. Tajima M, Sugita T, Nishikawa A, Tsuboi R: Molecular analysis of Malassezia microflora in seborrheic dermatitis patients: comparison with other diseases and healthy subjects. J Invest Dermatol 2008, 128:345-351.

36. Morishita N, Sei Y, Sugita T: Molecular analysis of Malassezia microflora from patients with pityriasis versicolor. Mycopathologia 2006, 161:61-65.

37. Gemmer CM, DeAngelis YM, Theelen B, Boekhout T, Dawson Jr TL Jr: Fast, noninvasive method for molecular detection and differentiation of Malassezia yeast species on human skin and application of the method to dandruff microbiology. J Clin Microbiol 2002, 40:3350-3357.

38. Takahata Y, Sugita T, Hiruma M, Muto M: Quantitative analysis of Malassezia in the scale of patients with psoriasis using a real-time polymerase chain reaction assay. Br J Dermatol 2007, 157:670-673.

39. Makimura K, Tamura Y, Kudo M, Uchida K, Saito H, Yamaguchi H: Species identification and strain typing of Malassezia species stock strains and clinical isolates based on the DNA sequences of nuclear ribosomal internal transcribed spacer 1 regions. J Med Microbiol 2000, 49:29-35.

40. Sugita T, Kodama M, Saito M, Ito T, Kato Y, Tsuboi R, Nishikawa A: Sequence diversity of the intergenic spacer region of the rRNA gene of Malassezia globosa colonizing the skin of patients with atopic dermatitis and healthy individuals. J Clin Microbiol 2003, 41:3022-3027.

41. Kano R, Aizawa T, Nakamura Y, Watanabe S, Hasegawa A: Chitin synthase 2 gene sequence of Malassezia species. Microbiol Immunol 1999, 43:813-815.

42. Hanifin J, Rajka G: Diagnostic features of atopic dermatitis. Acta Derm Venereol 1980, 60:44-47.

43. European Task Force on Atopic Dermatitis: Severity scoring of atopic dermatitis: the SCORAD index. Dermatology 1993, 186:23-31.

44. Ramsay B, Lawrence CM: Measurement of involved surface area in patients with psoriasis. Br J Dermatol 1991, 124:565-570. 
45. Fredriksson T, Pettersson U: Oral treatment of pustulosis palmo-plantaris with a new retinoid, Ro 10-9359. Dermatologica 1979, 158:60-64.

46. Clinical and Laboratory Standards Institute/National Committee for Clinical Laboratory Standards: Method for Antifungal Disk Diffusion Susceptibility Testing of Yeasts: Approved Guideline, Document M44-A. Wayne, PA: Clinical and Laboratory Standards Institute; 2000.

47. Kurtzman CP, Fell JW, Boekhout T, Robert V: Methods for isolation, phenotypic characterization, and maintenance of yeasts. In The Yeasts, a Taxonomic Study. 5th edition. Edited by Kurtzman CP, Fell JW, Boekhout T. Amsterdam: Elsevier; 2010:87-111.

48. Ashbee HR, Evans EGV: Immunology of diseases associated with Malassezia species. Clin Microbiol Rev 2002, 15:21-57.

49. Gupta AK, Kohli Y: Prevalence of Malassezia species on various body sites in clinically healthy subjects representing different age groups. Med Mycol 2004, 42:35-42.

50. Nakabayashi A, Sei Y, Guillot J: Identification of Malassezia species isolated from patients with seborrhoeic dermatitis, atopic dermatitis, pityriasis versicolor and normal subjects. Med Mycol 2000, 38:337-341.

51. Sugita T, Suto H, Unno T, Tsuboi R, Ogawa H, Shinoda T, Nishikawa A: Molecular analysis of Malassezia microflora on the skin of atopic dermatitis patients and healthy subjects. J Clin Microbiol 2001, 39:3486-3490.

52. Gaitanis G, Velegraki A, Alexopoulos EC, Chasapi V, Tsigonia A, Katsambas A: Distribution of Malassezia species in pityriasis versicolor and seborrhoeic dermatitis in Greece. Typing of the major pityriasis versicolor isolate M. globosa. Br J Dermatol 2006, 154:854-859.

53. Gupta AK, Kohli Y, Summerbell RC, Faergemann J: Quantitative culture of Malassezia species from different body sites of individuals with or without dermatoses. Med Mycol 2001, 39:243-251.

54. Affes M, Salah SB, Makni F, Sellami H, Ayadi A: Molecular identification of Malassezia species isolated from dermatitis affections. Mycoses 2009, 52:251-256.

55. Crespo Erchiga V, Ojeda Martos A, Vera Casaño A, Crespo Erchiga A, Sanchez Fajardo F: Malassezia globosa as the causative agent of pityriasis versicolor. Br J Dermatol 2000, 143:799-803.

56. Chaudhary R, Singh S, Banerjee T, Tilak R: Prevalence of different Malassezia species in pityriasis versicolor in central India. Indian J Dermatol Venereol Leprol 2010, 76:159-164.

57. Tarazooie B, Kordbacheh P, Zaini F, Zomorodian K, Saadat F, Zeraati H, Hallaji Z, Rezaie S: Study of the distribution of Malassezia species in patients with pityriasis versicolor and healthy individuals in Tehran, Iran. BMC Dermatol 2004, 4:5.

58. Ramadán S, Sortino M, Bulacio L, Marozzi ML, López C, Ramos L: Prevalence of Malassezia species in patients with pityriasis versicolor in Rosario, Argentina. Rev Iberoam Micol 2012, 29:14-19.

59. Kupryś-Lipińska I, Elgalal A, Kuna P: Epidemiology of atopic dermatitis in general population of the Lodz province's citizens. Pneumonol Alergol Pol 2009, 77:145-151.

60. Frankowska J, Kamer B, Trznadel-Budźko E, Rotsztejn H: The estimation of atopic dermatitis in infants and small children in general practitioner's practice - own observations. Wiad Lek 2011, 64:176-180.

61. Neneman A, Adamski Z: Clinical and epidemiological systemic disorders in psoriasis patients. Forum Med Rodz 2009, 3:447-453.

62. Sandström Falk MH, Tengvall Linder M, Johansson C, Bartosik J, Bäck O, Särnhult T, Wahlgren CF, Scheynius A, Faergemann J: The prevalence of Malassezia yeasts in patients with atopic dermatitis, seborrhoeic dermatitis and healthy controls. Acta Derm Venereol 2005, 85:17-23.

63. Prohić A: Identification of Malassezia species isolated from scalp skin of patients with psoriasis and healthy subjects. Acta Dermatovenerol Croat 2003, 11:10-16.

64. Zomorodian K, Mirhendi H, Tarazooie B, Zeraati H, Hallaji Z, Balighi K: Distribution of Malassezia species in patients with psoriasis and healthy individuals in Tehran. J Cutan Pathol 2008, 35:1027-1031.

65. Amaya M, Tajima M, Okubo Y, Sugita T, Nishikawa A, Tsuboi R: Molecular analysis of Malassezia microflora in the lesional skin of psoriasis patients. J Dermatol 2007, 34:619-624.

66. Sugita T, Saito M, Ito T, Kato Y, Tsuboi R, Takeuchi S, Nishikawa A: The basidiomycetous yeasts Cryptococcus diffluens and C. liquefaciens colonize the skin of patients with atopic dermatitis. Microbiol Immunol 2003, 47:945-950.
67. Chan GF, Puad MS, Chin CF, Rashid NA: Emergence of Aureobasidium pullulans as human fungal pathogen and molecular assay for future medical diagnosis. Folia Microbiol (Praha) 2011, 56:459-467.

68. Grice EA, Segre JA: The skin microbiome. Nat Rev Microbiol 2011, 9:244-253.

69. Gupta AK, Kohli Y, Li A, Faergemann J, Summerbell RC: In vitro susceptibility of the seven Malassezia species to ketoconazole, voriconazole, itraconazole and terbinafine. Br J Dermatol 2000, 142:758-765.

70. Hammer KA, Carson CF, Riley TV: In vitro activities of ketoconazole, econazole, miconazole and Melaleuca alternifolia (tea tree) oil against Malassezia species. Antimicrob Agents Chemother 2000, 44:67-69.

71. Xu J, Saunders CW, Hu P, Grant RA, Boekhout T, Kuramae EE, Kronstad JW, DeAngelis YM, Reeder NL, Johnstone KR, Leland M, Fieno AM, Begley WM, Sun Y, Lacey MP, Chaudhary T, Keough T, Chu L, Sears R, Yuan B, Dawson TL Jr: Dandruff-associated Malassezia genomes reveal convergent and divergent virulence traits shared with plant and human fungal pathogens. Proc Natl Acad Sci USA 2007, 104:18730-18735.

72. Gioti A, Nystedt B, Li W, Xu J, Andersson A, Averette AF, Münch K, Wang X, Kappauf C, Kingsbury JM, Kraak B, Walker LA, Johansson HJ, Holm T, Lehtiö J, Stajich JE, Mieczkowski P, Kahmann R, Kennell JC, Cardenas ME, Lundeberg J, Saunders CW, Boekhout T, Dawson TL, Munro CA, de Groot PWJ, Butler G, Heitman J, Scheynius A: Genomic insights into the atopic eczema-associated skin commensal yeast Malassezia sympodialis. mBio 2013, 4:16. 00572-12.

73. Kim D, Lim YR, Ohk SO, Kim BJ, Chun YJ: Functional expression and characterization of CYP51 from dandruff-causing Malassezia globosa. FEMS Yeast Res 2011, 11:80-87.

doi:10.1186/1471-5945-14-3

Cite this article as: Jagielski et al.: Distribution of Malassezia species on the skin of patients with atopic dermatitis, psoriasis, and healthy volunteers assessed by conventional and molecular identification methods. BMC Dermatology 2014 14:3.

\section{Submit your next manuscript to BioMed Central and take full advantage of:}

- Convenient online submission

- Thorough peer review

- No space constraints or color figure charges

- Immediate publication on acceptance

- Inclusion in PubMed, CAS, Scopus and Google Scholar

- Research which is freely available for redistribution 